\section{"MOÇOS INTRÉPIDOS AO LEO DA AVENTURA": O CLUBE CAMPINEIRO DE REGATAS E NATAÇÃO E A VIDA AO AR LIVRE (1918-1935)}

"INTREPID YOUTH LOOKING FOR ADVENTURE": THE CAMPINEIRO ROWING AND SWIMMING CLUB AND LIFE IN THE OPEN AIR (19181935) $C_{\oplus}$

"MOZOS INTRÉPIDOS A BORDO DE LA AVENTURA": EL CLUB CAMPINERO DE REGATAS Y NATACIÓN Y LA VIDA AL AIRE LIBRE (1918-1935) $\mathcal{C}_{\oplus}$

doi) https://doi.org/10.22456/1982-8918.113709

Catharina Ulian Musa* <catharinaulianmusa@gmail.com>

Daniele Cristina Carqueijeiro de Medeiros ${ }^{* *}<$ danieli_ccm@ hotmail.com>

(iD) Carmen Lúcia Soares* <soares.carmenlucia@gmail.com>

\footnotetext{
*Universidade Estadual de Campinas. Campinas, SP, Brasil.

${ }^{* *}$ Prefeitura Municipal de Campinas. Campinas, SP, Brasil.
}

Recebido em: 02 mai. 2021 Aprovado em: 13 jun. 2021 Publicado em: 28 ago. 2021

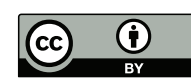

Este é um artigo publicado sob a licença Creative Commons Atribuição 4.0 Internacional (CC BY 4.0).

elSSN: $1982-8918$ 


\section{INTRODUÇÃO}

Em 18 de maio de 1918, deu-se início, em Campinas/SP, à construção do Clube Campineiro de Regatas e Natação (C.C.R.N)1 . O clube, que ambicionava desenvolver e estimular a prática de esportes aquáticos, teve sua localização escolhida no Arraial de Sousas, pequeno distrito localizado distante do centro da cidade de Campinas e que contava com um trecho navegável do rio Atibaia, principal via fluvial da região (PALOMBO, 2000, p.71).

Desde o final do século XIX, Campinas vivia transformações intensas, tanto economicamente quanto social e culturalmente. A recém-formada República, somada ao abolicionismo, e o crescimento da burguesia foram elementos importantes na formação e transformação do núcleo urbano da cidade (BADARÓ, 1996, LAPA, 2008). De acordo com Lapa (2008), foi nesse período que começaram a se desenhar transformações de sentidos para as palavras "velho" e "moderno", uma ganhando um significado pejorativo e a outra apontando os trilhos do século que chegaria. $\mathrm{Na}$ esteira dos novos significados desejados para a vida urbana, os esportes se estabeleciam como dimensão importante das novas sociabilidades.

Havia, há algum tempo, certa insatisfação a respeito da difusão dos esportes na cidade. De acordo com a imprensa, mesmo após a recente instalação do C.C.R.N., a cidade ainda se ressentia da falta de instituições desse tipo, bem como de praças e outras iniciativas que incentivassem a prática esportiva entre os jovens:

Sobre esporte... nada ou pouco temos que dizer.

A esse respeito, Campinas está infelizmente em tal situação de inferioridade em relação a quasi todas as cidades do nosso Estado, que até nos custa tocar num assumpto que só serve para pôr á mostra a falta de actividade, de energia e mesmo de bôa vontade dos esportistas campineiros. (REMO...1921, p.8)

Aos esportes eram atribuídas características como melhoria do caráter, da virilidade e da força (BOURDIEU, 2003); assim, sua difusão pela cidade era associada a inúmeros benefícios à população e à juventude. De acordo com Siqueira (2009), desde o início da década de 1910 já se exprimia o desejo, entre os sportmen² da cidade, da instalação de um clube voltado às práticas esportivas, especialmente o remo. Certamente esse desejo se associava à sua difusão em outras cidades, como São Paulo (NICOLINI, 2001), Rio de Janeiro (LUCENA, 2001; MELO, 2001), Porto Alegre (SILVA, 2011; SILVA, MAZO, TAVARES, 2018), Fortaleza (MONTENEGRO, 2020), Belém (DIAS, 2014; DIAS; SOARES, 2014), entre outras. Além disso, ao remo e à natação eram atribuídas características positivas que os tornavam, inúmeras vezes, os esportes mais indicados para os jovens, como, por exemplo, a perseverança, a intrepidez e a confiança (MELO, 1999; SILVA, 2011).

\footnotetext{
1 O Clube Campineiro de Regatas e Natação é uma instituição tradicional da cidade de Campinas/SP que atua ininterruptamente desde 1918 até os dias de hoje. O Clube nasceu às margens do rio Atibaia com o intuito de promover o remo e a natação. A partir de 1935, com a inauguração de sua sede urbana, outros esportes começaram a ser praticados, tanto por atletas quanto por seus associados (PALOMBO, 2000).

2 No Brasil, a partir da difusão das práticas esportivas em diferentes cidades, o termo sportmen começou a ser adotado pela imprensa para definir um conjunto de pessoas envolvidas com os esportes, como atletas, treinadores e associados de diversos clubes. De acordo com Melo e Santos (2020, p.503), o aumento na popularidade dos esportes fez com que esse termo se tornasse mais abrangente, e passasse a designar "quem adotava comportamentos julgados modernos: uma maneira mais leve de se vestir, posturas menos formais, hábitos mais ativos e ousados."
} 
A inauguração de um clube que tinha o remo como principal prática esportiva exigia a presença de rios, mares ou lagoas. O Atibaia era a única opção possível na cidade de Campinas. Esse rio era já um velho conhecido de parte da população e bastante utilizado para inúmeras atividades ribeirinhas, como a lavação de roupas, a pescaria, os banhos e os alegres pulos na água. A instalação de um clube na região em que o rio cortava o Arraial de Sousas, pouco habitado e ainda não urbanizado, promoveu uma profunda transformação nessas atividades, antes ligadas somente ao mundo do trabalho e dos divertimentos. A prática esportiva exigiu uma intervenção no rio; ela pretendeu usos, gestos e condutas inéditas frente a esse espaço da natureza (SIQUEIRA, 2009; MUSA, 2021).

O artigo é desenvolvido num recorte de tempo que compreende os anos de 1918 a 1935. O ano de 1918 é aquele de instalação do C.C.R.N. às margens do rio Atibaia, no distrito de Sousas, destinado à prática do remo, da natação e de um conjunto de divertimentos ao ar livre. O ano de 1935 é aquele que consolida os esforços da diretoria e de seus associados na criação de uma sede urbana na qual os esportes e divertimentos ao ar livre, desenvolvidos majoritariamente no Arraial de Sousas, deixaram de ter centralidade para a instituição, que amplia o número de esportes praticados, bem como de eventos associativos e recreativos. Nesse período recortado, o artigo tem como objetivo examinar como sua instalação às margens do Atibaia transformou a relação da população local com a natureza e seus elementos, mediada, a partir desse momento, por novas práticas e condutas ligadas à cultura física.

Em termos metodológicos, realizamos uma pesquisa de cunho bibliográfico e documental cujas fontes foram constituídas por jornais, revista, fotografias, recortes avulsos de jornais que estão sob a guarda do Centro de Memória da Unicamp (CMU) e imagens disponibilizadas pelo CMU e pelo Museu da Imagem e do Som -Campinas (MIS).

\section{EM BUSCA DE VESTÍGIOS}

Parece ser consenso entre historiadores(as) do esporte que jornais e revistas são importantes fontes para o estudo das práticas esportivas e do cotidiano dos clubes esportivos. A difusão do esporte em um cenário mundial, no início do século $\mathrm{XX}$, fez com que essa prática fosse cobiçada por aqueles responsáveis por "fazer opinião", já que, de acordo com Vigarello (2008), era possível associar ao esporte mensagens e propagandas. Para o autor, a nova arte de narrar o esporte foi muito importante para sua difusão mundo afora. Ao mesmo tempo, o esporte foi capaz de movimentar o mercado de jornais e revistas, dado seu amplo consumo pela população (VIGARELLO, 2002). Assim, esse artigo tomou a imprensa como fonte e selecionou: uma revista campineira ( $A$ Onda), bem como um jornal paulistano ( $A$ Gazeta), além de recortes avulsos de jornal com recorrências ao C.C.R.N.

A revista A Onda circulou na cidade de Campinas entre os anos de 1921 e 1924, totalizando setenta números. De acordo com Corrêa (2014), a revista surgiu com um programa voltado ao humorismo, e foi grande expoente dos eventos sociais 
que ocorriam na cidade à época. Assim, em diversos números foram encontradas reportagens a respeito do C.C.R.N., em especial narrativas que remontavam a festas e bailes.

O jornal $A$ Gazeta teve importante participação na difusão dos esportes na cidade de São Paulo, assim como no interior. O jornal surgiu em 1906, mas foi na década de 1930 que alcançou grande sucesso com o público. Desde seus primeiros números contava com uma pequena seção esportiva. Na década de 1920, esta seção se tornou um suplemento do jornal e, mais tarde, em 1947, ganhou contornos próprios com a inauguração d'A Gazeta Esportiva, que ainda circula em formato digital (TOLEDO, 2012). O periódico abordava os esportes como elementos que auxiliariam as cidades paulistas a atingirem um novo patamar, com competitividade, competência e organização (TOLEDO, 2012). O seu modo de elaborar um jornalismo esportivo também foi bastante inovador. As páginas dedicadas às notícias esportivas sempre tiveram a intenção de ganhar feição popular, e suas narrativas, associadas à publicação de fotografias, reiteravam esse ideal a todo tempo (TOLEDO, 2012). Com papel importante na divulgação dos esportes, o jornal, sob o comando de Cásper Líbero, também foi responsável por promover grandes eventos, como a Travessia de São Paulo a Nado. Os eventos realizados nos clubes de regatas paulistanos eram narrados na seção Rowing, que, esporadicamente, falava também dos eventos esportivos do interior, com destaque para Campinas e Piracicaba.

Além da revista e do jornal, foram utilizados recortes de jornais diversos que se encontravam no acervo do CMU. Esses recortes têm datações distintas dos limites temporais deste artigo, mas, ainda assim, foram utilizados, pois, em geral, tratam de reportagens comemorativas cujo conteúdo memorialístico se reporta a eventos realizados pelo clube.

Por fim, o artigo também se debruça sobre o universo da fotografia ${ }^{3}$, considerando sua expressiva presença nos acervos consultados pertencentes ao $\mathrm{MIS}^{4}$ e ao CMU que remontam ao cotidiano do Arraial de Sousas mesmo antes da instalação do C.C.R.N.

\section{O RIO: NOVAS RELAÇÕES COM A NATUREZA E O ADVENTO DOS ESPORTES}

\footnotetext{
Com o fim de estudar a installação, designada para breve, do Club Campineiro de Natação e Regatas, seguiram hontem, ás 9 horas, em bonde especial para o Arraial dos Sousas, a directoria da agremiação citada. [...]

Foi estudado o rio Atibaia quanto á sua largura e extensão em que poderão ser disputadas as regatas, e verificados, também os pontos em que se tem de fazer extracção de grandes pedras.
}

(O CLUB..., 1918b, p.2)

\footnotetext{
3 Ao longo do século $X X$ os historiadores passaram a considerar imagens (pinturas, desenhos, fotografia) como fonte legitima para a análise do passado. Sobre esse uso ver, entre outros, (LE GOFF; NORA, 1988, SONTAG, 2004; KOSSOY, 2012).

4 As fotografias do MIS utilizadas nesse artigo fazem parte da coleção Austero Penteado, composta por 292 imagens fotográficas que retratam a vida rural e urbana de Campinas no início do século $\mathrm{XX}$, com atenção especial à região de Sousas, local onde Penteado tinha uma fazenda.
} 
Logo após o anúncio da inauguração do Clube de Regatas, deu-se a citada excursão, que teve como objetivo analisar e transformar o rio, para que ele ficasse navegável e utilizável para as práticas esportivas. Não seria possível iniciar as competições, aulas e desafios sem antes modificar o espaço, que ainda não era dominado pela mão humana.

A instalação do novo clube em uma zona distante do centro da cidade - o Arraial de Sousas - trazia duas consequências. Uma delas era a possibilidade de proporcionar a seus associados um contato mais próximo com a natureza e com as águas do rio, sem a interferência dos elementos urbanos. A outra consequência era o distanciamento das facilidades produzidas pela mão humana, como largas estradas ou energia elétrica.

A Figura 1 retrata enquadramento de uma natureza que começa a ser modificada. Se as margens convidam à contemplação, o rio, às brincadeiras; é possível constatar também traços do trabalho humano. Assim, é em meio a uma paisagem que sofre pequenas intervenções que o C.C.R.N. tem sua instalação.

Figura 1 - Ponte sobre o rio Atibaia em Sousas, [1901-1919]

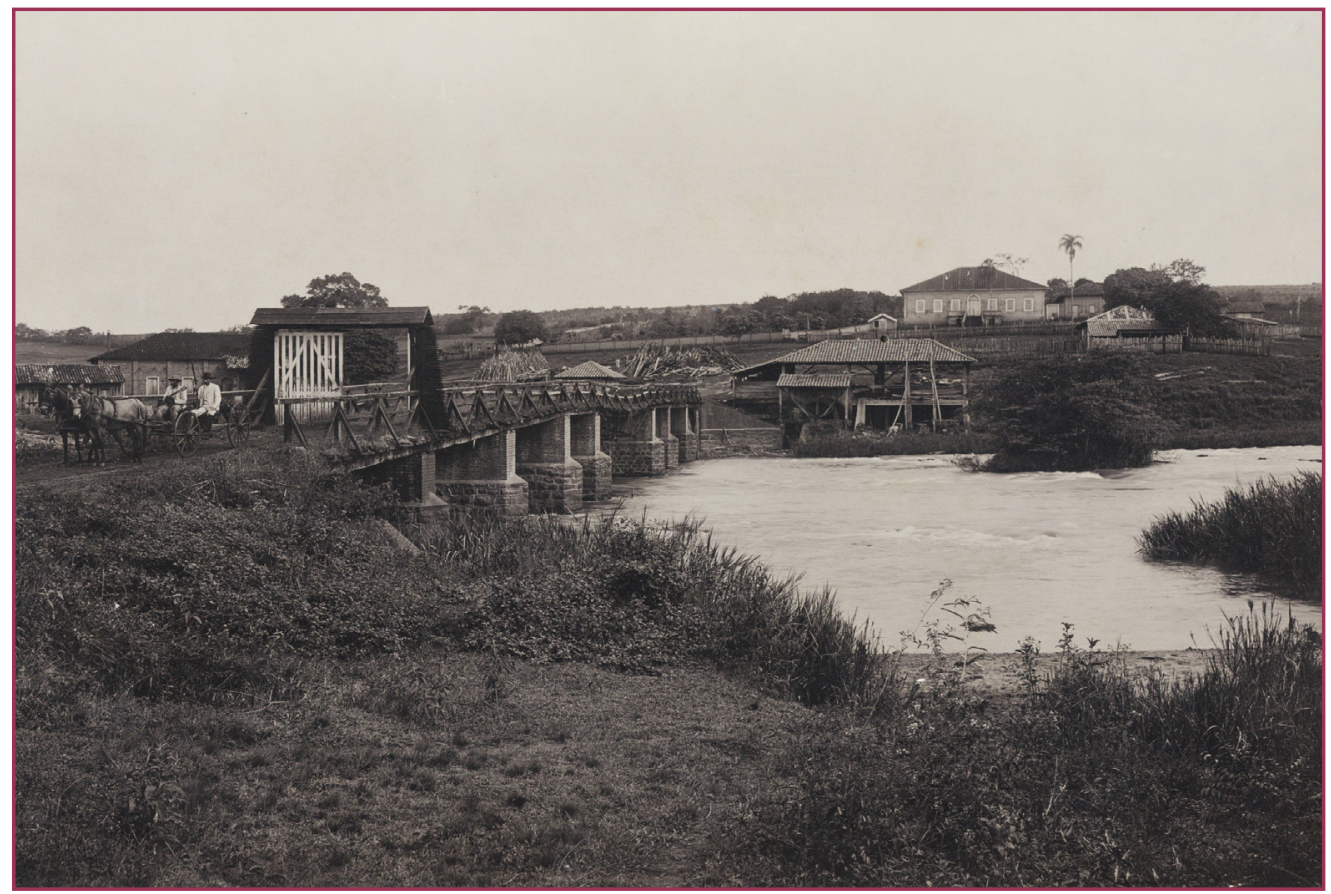

Fonte: Museu da Imagem e do Som/Campinas - Coleção Austero Penteado

O Arraial de Sousas, denominação dada à região desde 1889, era composto, no período analisado neste artigo, por propriedades rurais, que se dedicavam principalmente ao plantio do café, e um pequeno núcleo populacional que, no início do século XX, contava com aproximadamente duas mil pessoas (TíRICO, 1960). Sua distância do principal núcleo da cidade de Campinas era grande, e foi encurtada pela inauguração de uma estrada de ferro, na década de 1880, com o objetivo de escoar a produção local do café. (TíRICO, 1960).

Essa região estava apartada das transformações urbanas pelas quais passava a cidade de Campinas. De acordo com Roxo (2020), desde a Proclamação 
da República, Campinas havia se tornado uma cidade que ambicionava a modernização, principalmente com a expansão das indústrias, aumento da região urbana e adensamento da rede de técnicos e burocratas. Paulatinamente houve uma mudança de bases econômicas agrárias para industriais, que se apoiavam no desenvolvimento da cidade para seu sucesso (ROXO, 2020). Tais transformações foram acompanhadas de mudanças também na vida cotidiana, nas práticas e costumes, que se adequavam às novas realidades (LAPA, 2008).

De acordo com fontes reunidas para este artigo, o Arraial de Sousas era até a época da instalação do C.C.R.N., uma "minúscula gleba povoada" (BIANCHI, 1964, p.1), e a chegada até o local exigia um enorme dispêndio de tempo, o que fazia com que muitas vezes os esportistas se deslocassem em direção ao clube na madrugada e voltassem apenas no período da noite (AMENDOLA, 1961).

Ainda que pouco aproveitado pelos habitantes da região central de Campinas, o rio Atibaia não foi "descoberto" pela população quando o C.C.R.N. foi inaugurado em suas margens. Ao contrário, suas águas já eram utilizadas pela população do Arraial de Sousas para inúmeras atividades, como, por exemplo, a lavagem de roupas, os passeios, as pescarias e o transporte, como sugerem as Figuras 2 e Figura 3.

Figura 2 - Pescadores no rio Atibaia [1901-1919]

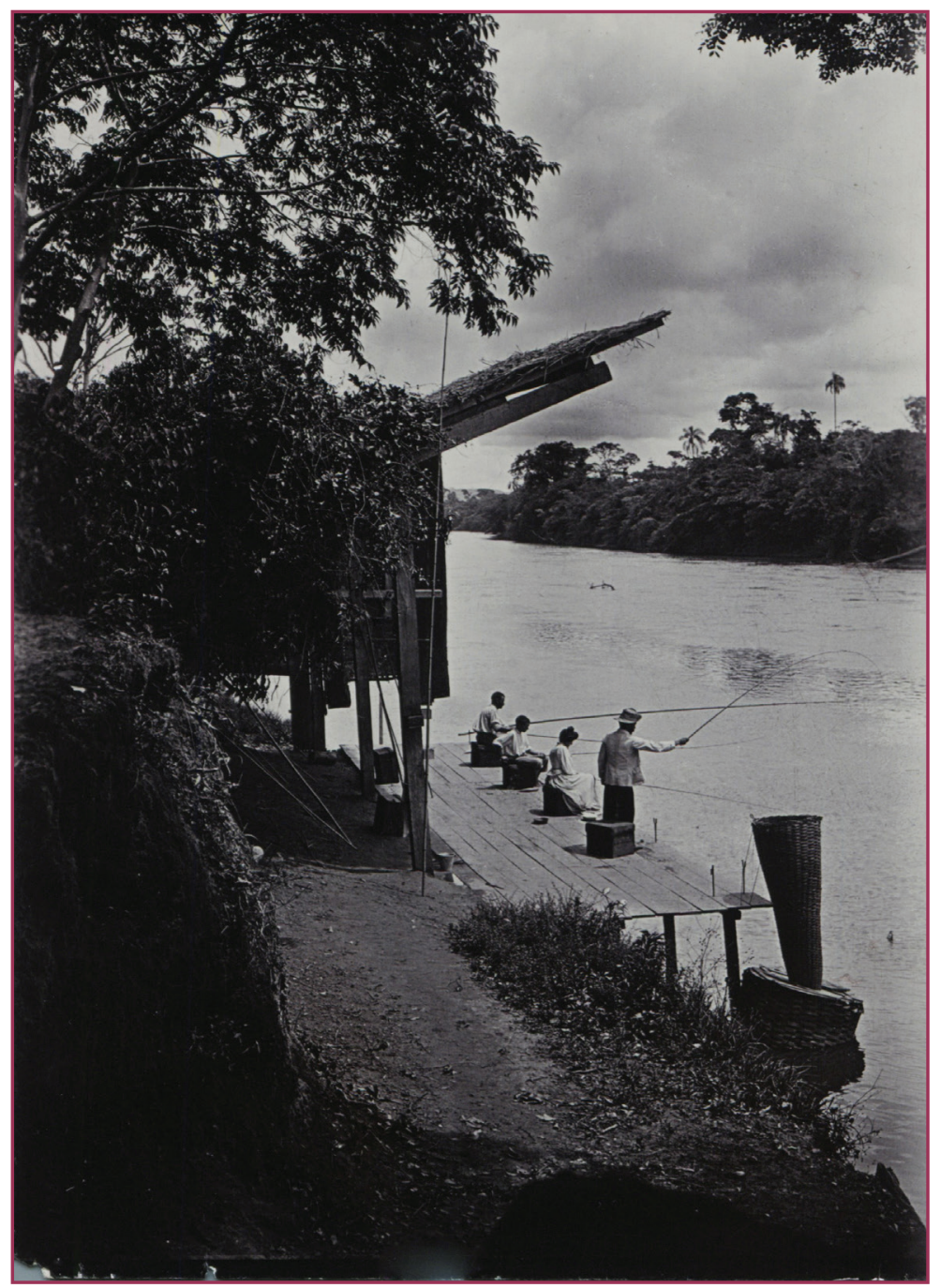

Fonte: Museu da Imagem e do Som/Campinas - Coleção Austero Penteado 
Figura 3 - Passeio no rio Atibaia, [1901-1919]

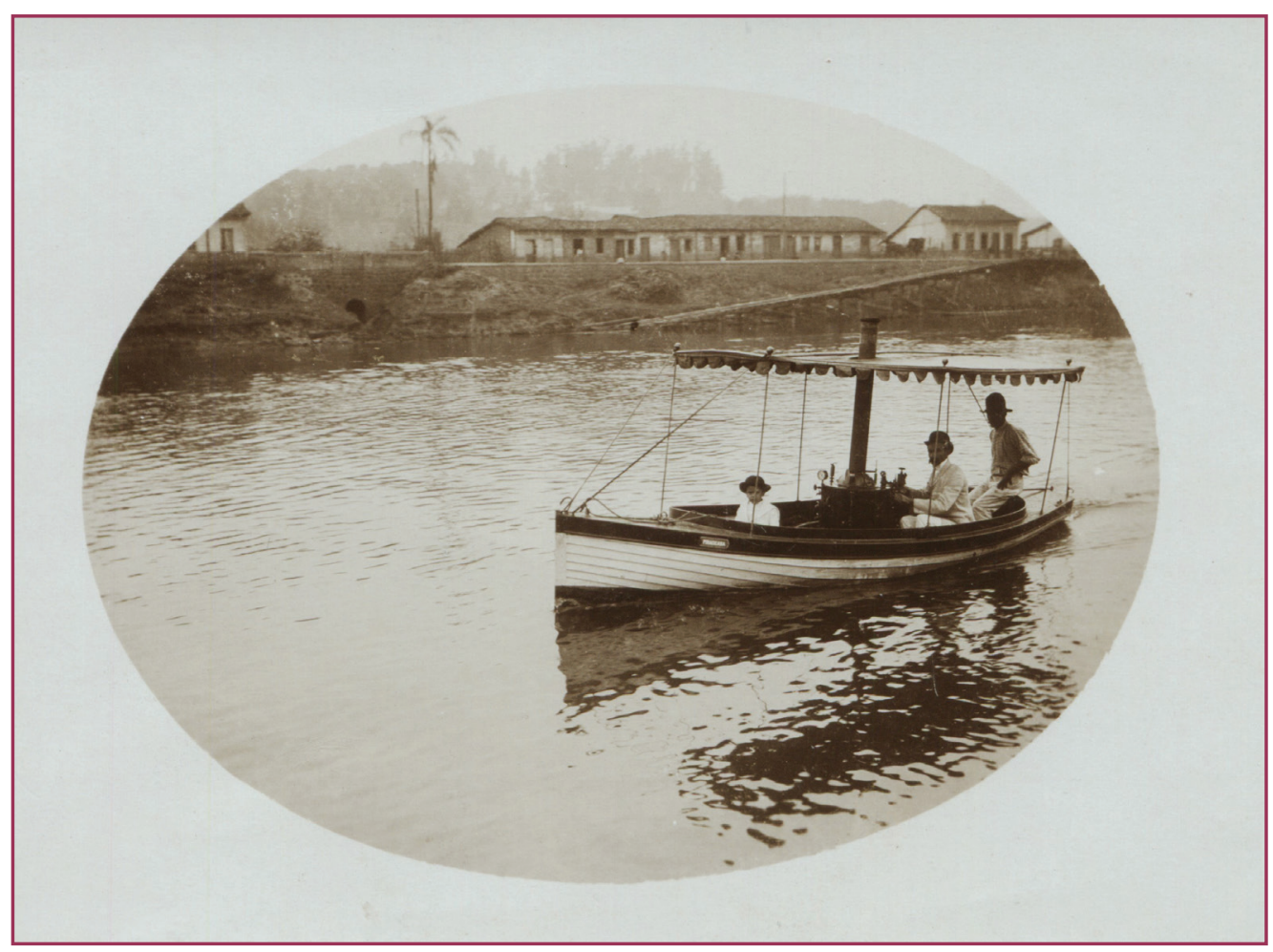

Fonte: Museu da Imagem e do Som/Campinas - Coleção Austero Penteado

Essa dúbia relação existente entre os benefícios e malefícios da instalação do clube em um local distante da zona mais central da cidade refletia as expectativas em relação ao contato com a natureza e as definições de vida ao ar livre nesse período, no Brasil. Embora há séculos a natureza já tivesse sido associada à promoção de benefícios à saúde, especialmente em contraste aos malefícios da urbanização, no Brasil, um ideário de vida ao ar livre se instituiu entre fins do século XIX e início do XX (SOARES, 2016).

Caberia, então, retomar aqui a longa tradição no âmbito do pensamento ocidental acerca da natureza e seus elementos associados a benefícios voltados à saúde, a ideais sanitários e, ao mesmo tempo, a possibilidades educativas. Trata-se aqui de um extenso processo de produção e de transformação de noções e conceitos que permitiram que o mundo natural fosse reabilitado. Para Thomas (1988, p.18), os anos de 1500 e 1800 foram aqueles

[...] em que ocorreu uma serie de transformações na maneira pela qual os homens e mulheres, de todos os níveis sociais, percebiam e classificavam o mundo natural ao seu redor [...]. Surgiram novas sensibilidades em relação aos animais, às plantas e à paisagem [...].

Como escreveu Soares (2016, p.10), as transformações evocadas por Thomas constituíram um processo

[...] complexo e conflituoso, pois, contrapondo-se a crenças religiosas ou não, mobilizou pensamentos diversos conformando, a cada época, compreensões e proposições sobre a natureza, carregadas do tempo em que foram concebidas, vividas, exaltadas, esquecidas ou abandonadas. É desse modo que a natureza parece ser, a cada época, redescoberta, ou mesmo inventada, pois, construção histórica. 
Podemos aqui dialogar, também, com Lenoble (1990), autor que desenvolve uma discussão acerca das ideias de natureza afirmando que elas somente encontram sentido na história; ou seja, uma ideia de natureza é expressão de atitudes humanas em relação a ela e não à passividade de uma realidade. Essas atitudes face ao mundo natural se transformam ao longo da história tanto pela influência da religião como da ciência. Não seria anódino afirmar aqui que a contemplação de um lugar é sempre "[...] carregada daquilo que se sabe, que se pode saber, ou, ainda que se deseja saber, tal qual são os usos que se fazem desse mesmo lugar "contemplado" [...]" (SOARES, 2016, p.11).

Uma certa reabilitação da natureza ${ }^{5}$ e seus elementos em seus aspectos benéficos se consolida pouco a pouco, sendo o século XVIII o período em que novas sensibilidades são produzidas e um discernimento sensorial se expande. Corbin (2001) vai afirmar que, neste século, as atitudes humanas em relação à paisagem, por exemplo, mobilizam todos os sentidos e não apenas a visão. Trata-se, portanto, de um período que afirma novas sensibilidades resultantes de novas relações com a natureza de modo que,

[...]Ao fim do século XVIII, a sociedade ocidental experimenta, efetivamente, uma evolução da sensibilidade no que diz respeito às relações entre os seres humanos e a natureza com seus elementos. Os rastros de uma ideia de natureza benevolente e generosa, cara ao pensamento de Rousseau, podem ser percebidos, ainda, na aurora do século XX. No Brasil, particularmente nas capitais ou em cidades mais populosas, o ideário de vida ao ar livre, de naturezas domesticadas e inventadas pela nova ordem urbana se faz presente, misturando cura e divertimento, educação e saúde. [...] (SOARES, 2016, p.17).

Diversas cidades brasileiras que se urbanizavam se valeram de discursos que elegiam a vida em meio à natureza como mais benéfica que aquela na cidade, como, por exemplo, o Rio de Janeiro, São Paulo, Curitiba e Fortaleza (DALBEN, 2009; DALBEN, 2014; DALBEN, 2016; DALBEN; SILVA, 2020; MONTENEGRO, 2020; SOARES, 2016; MORAES; SILVA, QUITZAU; SOARES, 2018). Esses discursos, postulados por médicos, higienistas, arquitetos e professores, promoviam estratégias de aproximação e aproveitamento da natureza.

O modo de vida urbano, que começa a ganhar força na cidade de Campinas, nutre-se, também, de inéditas concepções acerca da natureza e seus elementos, sobretudo daquelas que expressam benevolência e beleza. Constatam-se, por exemplo, mudanças arquitetônicas importantes que abrem espaço para a inclusão de distintas áreas verdes, como praças e parques. Além disso, ruas arborizadas são instaladas, ao mesmo tempo em que são desenvolvidos códigos sanitários, criados em função da gravidade de doenças e epidemias que se espalhavam no meio urbano (CARPINTERO, 2013; LAPA, 2008). Pode-se afirmar que se tratava de procedimentos que tomavam praças, jardins públicos e parques como espaços de uma natureza controlada pela mão humana, aprazível e benfazeja. São esses lugares que acolhem, também, um conjunto de práticas como passeios, piqueniques, caminhadas e esportes.

No que se refere aos esportes, havia um desejo de difundi-los e, cada vez mais, assinalar os benefícios dessa prática em meio à natureza. Foi nesse período

5 Para o assunto, importante é a leitura de Rousseau (1992; 2005). Ver, também, Villaret (2005; 2016). 
que inúmeros clubes e associações esportivas se instalaram nas margens dos rios e à beira-mar em diversas cidades brasileiras (MELO, 1999; SILVA, 2011). Esses clubes e associações elegiam prioritariamente a natação e o remo e, de certo modo, foram tomados como modelo para a criação do C.C.R.N. (SIQUEIRA, 2009).

Instalar um clube à beira de um rio ou à beira-mar não era uma tarefa simples e exigia intervenções profundas do próprio espaço de natureza para que pudesse acolher as práticas com seus novos valores e sensibilidades. Não se tratava mais do mundo rural, e sim de uma natureza dominada pela mão humana, palco de novos modos de vida.

As primeiras intervenções no espaço escolhido para a instalação do C.C.R.N. começaram antes mesmo de sua inauguração. Em período imediatamente anterior a 1918, a Companhia de Tração, Luz e Força de Campinas abriu uma linha de bondes elétricos em direção a Sousas. De acordo com alguns jornais da cidade, a Companhia viu na instalação do clube uma boa oportunidade de aumentar o número de passageiros e foi uma grande incentivadora das construções que se seguiram, o que incluiu a doação de partes do terreno. Além disso, a Companhia doou também os recursos financeiros utilizados para a compra da primeira embarcação do clube (EM FESTAS...,1961; O QUE O TEMPO..., 1973).

A escolha do Arraial de Sousas preconizava a adoção de uma vida ao ar livre somada à prática de exercícios. As transformações que foram paulatinamente realizadas na região adaptaram os elementos da natureza em benefício das práticas esportivas, como apontado na epígrafe deste item. De acordo com Gambeta (2014), a arquitetura dos clubes esportivos refletia certa nostalgia da vida no campo somada aos gostos da nova elite urbana. Em relação ao C.C.R.N., isto se materializou na arborização de alamedas, pontos de passagem obrigatória para os associados (A ONDA, 1924).

Rapidamente os jornais e revistas que narravam as atividades do clube passaram a difundir os benefícios do contato com a natureza amena do local. Os domingos, dias em que os associados passeavam de barco pelas águas do Atibaia, eram retratados como dias "aprazíveis e insubstituíveis" (REGATAS..., 1938, p.2).

A presença de um clube esportivo às margens do rio Atibaia significaria não só transformações físicas nas margens ou a adoção de novas práticas durante os finais de semana. Significaria, para além disso, a adoção de novos paradigmas, associados à presença de um elemento da cultura física.

A cultura física ${ }^{6}$, de acordo com Kirk (1999), é muito mais do que a prática de exercícios físicos. Para além de práticas como as ginásticas e os esportes, esse conceito congrega a construção de novos discursos a respeito do corpo que se engendraram em uma rede de significados produzidos ao longo do tempo. Isso significa que a realização de esportes e exercícios exigia de seus participantes uma nova conduta, regulada por discursos médicos, educacionais e higiênicos (MORAES E SILVA; QUITZAU; 2018).

6 No Brasil esse conceito vem sendo utilizado na realização de pesquisa históricas a respeito do estudo do esporte, da Educação Física e das práticas associativas. Ver, entre outros: Medeiros, 2021; Moraes e Silva (2011); Moraes e Silva, Quitzau e Soares (2018); Moraes e Silva; Quitzau (2018). 
O remo já ganhava contornos que o tornavam um esporte bastante diferenciado no Brasil. De acordo com Lucena (2001) e Melo (1999; 2001), um dos primeiros locais em que o remo foi tomado como prática esportiva no Brasil foi o Rio de Janeiro, já no início do século XIX. Para os autores, um cenário modernizador se colocava no horizonte da cidade, e esta prática esportiva corroborava os anseios relativos ao futuro da então capital brasileira.

Cabe assinalar, contudo, que não foi somente no Rio de Janeiro da época que esse esporte ganhou significados próprios do mundo urbano. No Rio Grande do Sul os clubes de remo se autointitulavam promotores de saúde e de corpos belos, além de reafirmarem as identidades dos estrangeiros que os fundavam (SILVA, 2011; SILVA, MAZO, TAVARES, 2018). Em São Paulo os clubes de regatas, situados às margens dos rios Tietê e Pinheiros, se valiam de discursos que os postulavam como grandes promotores do esporte na cidade, aliando uma moral esportiva às práticas do remo e da natação (MEDEIROS, 2020).

Em Campinas havia também um apreço por tais características tão próprias ao remo. As reportagens reafirmavam a importância da prática e a associavam à coragem e aos benefícios da vida ao ar livre:

[O C.C.R.R.] foi fundado em 1918 por um pugilo de jovens enthusiastas. Aquella pleiade de desportistas, procurando inculcar no espirito da nossa mocidade o gosto pela prática do campismo e consequentemente á da educação physica, iniciaram a frequencia semanal ao retirado parque banhado pelo caudaloso Atibaia, propagando em alto e bom som os benefícios advindos da vida ao ar livre (REGATAS..., 1938, p.2).

A força de vontade dos remadores e nadadores, que se empenhavam nos treinamentos do clube, foi exaltada também nas páginas do jornal $A$ Gazeta, em 1923. A reportagem afirmava que os associados, a despeito da distância, treinavam regularmente na sede do clube, sem se importar com as dificuldades no transporte e acesso em direção ao Arraial de Sousas (CLUBE...,1923).

Paulatinamente, é possível perceber que a instalação do C.C.R.N. trouxe novas concepções e compreensões acerca dos usos do rio Atibaia e seu entorno na região de Sousas. À calmaria e ao bucolismo próprios à contemplação agregam-se as práticas esportivas e competitivas. O clube, assim, instaura e exorta a vida ao ar livre.

\section{O CLUB CAMPINEIRO DE REGATAS E NATAÇÃO: PROMOÇÃO DA CULTURA FÍSICA NO ARRAIAL DE SOUSAS}

As associações e clubes esportivos instalados em diferentes continentes se constituíram a partir da reunião de grupos de pessoas que compartilhavam um gosto comum pela realização de exercícios físicos, jogos e esportes, e, em muitas vezes, sua finalidade era organizar e tornar viáveis essas práticas (VIGARELLO, 2008). Arnaud (1986) chama esses clubes de microssociedades, locais em que foi necessário difundir ideais e valores para que todos compartilhassem de códigos comuns necessários à realização dessas práticas. No Brasil, essas associações também serviram como base de conformação e afirmação de inúmeras identidades, 
bem como auxiliaram na consolidação dos significados atribuídos à prática esportiva (SILVA et al., 2016; QUITZAU, 2019). Além desse caráter, os clubes foram lócus importantes de institucionalização e burocratização das práticas esportivas (ARNAUD, 1986; VIGARELLO, 2008).

O C.C.R.N também criou e difundiu um ideário esportivo a seus associados e investiu na transformação de práticas de divertimento realizadas no rio Atibaia, buscando instaurar uma ordem esportiva. O aumento no interesse pela atividade clubística, suas práticas e outros serviços oferecidos fez com que, nos primeiros anos de existência, a instituição procurasse definir quais eram seus objetivos, competências e regras. Era preciso ensinar aos novos associados como ser esportivo, os benefícios da cultura física promovida, como se comportar durante um jogo, quais os aspectos positivos do esporte que deveriam ser incentivados e quais as práticas rejeitadas pelo clube. Novas condutas ligadas à cultura física eram assinaladas, condutas essas que, em sua gênese, deveriam se distinguir das práticas locais e ribeirinhas.

De acordo com reportagem de recortes avulsos do jornal Diário do Povo, publicada quando o clube completou 50 anos, o lema da agremiação, desde sua fundação, foi a prática do esporte pelo esporte, "procurando não tanto fazer campeões, mas preparar atletas e burilar cidadãos na mais perfeita definição do mens sana in corpore sano" (REGATAS...1968). A reportagem, de caráter celebrativo, que tinha como intuito construir uma imagem positiva do clube, seguiu afirmando que, ao longo de todo o tempo de existência, a instituição se constituiu das mesmas diretrizes, incentivando a competitividade com disciplina e respeito ao adversário, na vitória ou na derrota (REGATAS...1968).

Para Vigarello (2002), a cultura física e as práticas esportivas não são um fenômeno desinteressado; muito pelo contrário, o esporte surge como um projeto educativo, voltado para a mobilização dos jovens. Bourdieu (2003, p. 141) sublinha que o esporte educava para "a energia, coragem, virtude de líderes [...]". Em vista de tais objetivos, os clubes esportivos não deixaram de pensar nos elementos morais envolvidos nas práticas ali realizadas. A cultura física que se expandia no C.C.R.N. preconizava a adoção de novos padrões de comportamentos de seus esportistas.

Tratava-se, assim, de estabelecer certa vigilância sobre a conduta dos associados seja em relação aos comportamentos, seja em relação às vestimentas para a prática esportiva. Símbolo de diferenciação das equipes, que, inclusive, eram conhecidas pelas cores que vestiam, o uniforme fazia parte também do código moral da boa prática esportiva. Para Soares (2011, p.93), a especialização dos discursos científicos sobre a prática dos exercícios físicos transformou as roupas e os calçados esportivos em artefatos privilegiados de atenção:

[...] se o ato de se vestir de maneira especial para atividades distintas já era algo dado nesse período, sua extensão para as práticas corporais e esportivas foi uma novidade que pôs em xeque valores, ultrapassou fronteiras, libertou e oprimiu corpos em movimento.

No C.C.R.N. a ausência de uniformes virou caso de polícia no ano de 1933. O diretor da modalidade do remo, Hipolito Leonardi, precisou acionar as autoridades para fazer com que alguns remadores do clube utilizassem os uniformes enquanto 
realizavam os treinamentos esportivos, já que a ausência deles "contrariava os estatutos e as boas maneiras da época” (O QUE O TEMPO...,1973).

Aausência de uniformes tornava-se ainda mais problemática quando associada ao remo, um esporte que tinha conotações positivas no que dizia respeito à formação integral do ser humano, seja física, mental ou social. O remo era constantemente evocado como o esporte "da saúde; do desafio, contra o outro e contra o mar, que educa o músculo e a moral; o esporte da velocidade; do progresso, do limpo e do belo" (MELO, 2001, p. 77), e seus praticantes deveriam, portanto, prezar pela boa conduta esportiva.

Na revista $A$ Onda, é possível constatar certa exaltação de valores positivos do remo. Na descrição de um final de semana em que se desenvolvia uma competição, destaca-se o ardor com que os competidores disputavam os páreos. A revista sublinhou "as peripécias, com que se desenrolaram as diversas competições, o enthusiasmo dos assistentes, as diferenças diminutas entre os vencedores e os respectivos adversários" (REMO...,1921, p.8).

Os remadores eram considerados nas próprias publicações do clube pessoas audazes e corajosas. A denominação "moços intrépidos ao leo da aventura" (BIANCHI, 1964, p.1), mencionada também no título deste artigo, foi atribuída aos remadores do clube, e resumia os sentidos que se desejava atribuir a este esporte, que desenvolveria a coragem, as habilidades e tornaria os jovens campineiros menos subjugados aos desafios, especialmente aqueles ocasionados pela natureza ainda inexplorada. Trata-se de uma síntese daquilo que o remo representava ao clube: a exortação da energia, da coragem, da virtude e da moral.

Figura 4 - Remadores do C.C.R.N., s/d

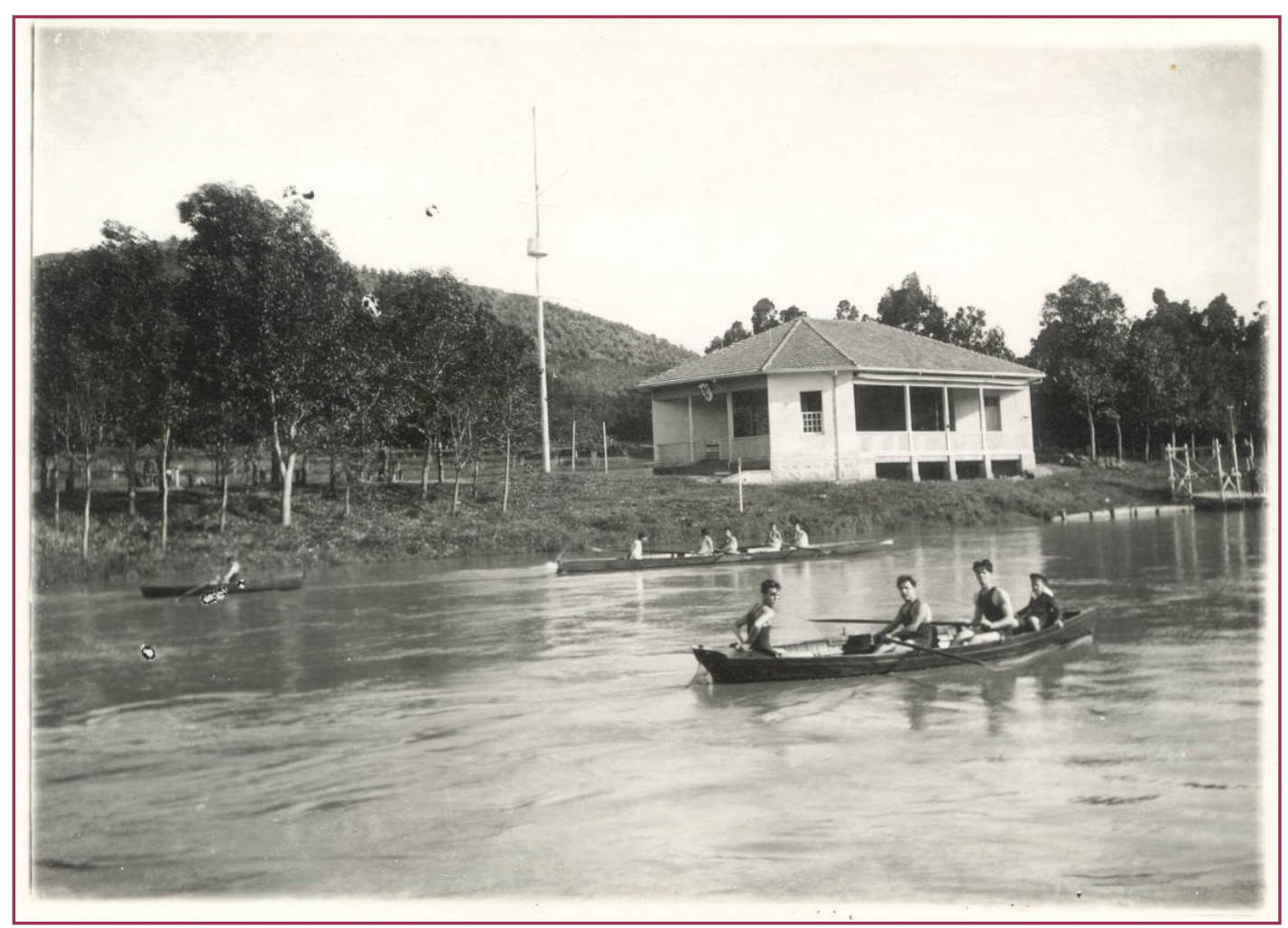

Fonte: Centro de Memória da Unicamp (CMU), Coleção V8 
A Figura 4 traz enquadramento da prática do remo, em que se veem três embarcações em plena atividade, emolduradas pela natureza exuberante das margens do Atibaia. No que tange às práticas esportivas, o clube logo se instituiu como o representante da cidade nos desafios aquáticos regionais. No final da década de 1910, outros desafios mais institucionalizados já se encontravam distribuídos entre a capital paulista e Santos em alto nível de competitividade (MEDEIROS, 2021).

Seu maior adversário era o Clube de Natação e Regatas de Piracicaba, fundado no início do século $X X$, mas que foi reestruturado no mesmo ano em que o C.C.R.N. surgiu (O CLUB...,1918a p. 2). Essas associações se tornaram grandes rivais na década de 1920, movidas pela proximidade geográfica. Além disso, nenhum dos dois fazia parte do quadro de clubes filiados à Federação Paulista de Sociedades do Remo (NICOLINI, 2001) e, na ausência de competições oficiais, se enfrentavam em páreos realizados em Campinas ou em Piracicaba.

O jornal A Gazeta, disseminador de informações sobre o remo e os clubes de regatas nas primeiras décadas do século $X X$, tratava de anunciar as competições que ocorreriam entre os dois clubes. As reportagens do jornal se prestavam tanto à divulgação das datas de realização de competições para promover os páreos e atrair o público quanto à narração dos fatos ocorridos que contavam com adjetivações heroicas e impressionantes (A CONVITE...., 1922).

Em maio de 1924, após realização de competição entre os dois clubes, o jornal apresenta longa reportagem narrando os feitos do final de semana. O programa de competições contou com provas de remo, natação e atletismo. As competições foram pormenorizadas e os vencedores laureados com seus nomes estampados no jornal. Por fim, a agremiação piracicabana obteve a maioria das vitórias, com apenas duas derrotas entre todos os páreos disputados (NAUTICA,1924).

Dentre todas as atividades realizadas pelo clube em seus primeiros anos de existência, não se encontravam apenas os esportes; uma ampla gama de atividades e festas animava os finais de semana.

Os clubes esportivos instalados no Brasil entre o final do século XIX e início do $X X$, muitas vezes por imigrantes, não se imbuíam apenas da difusão dos esportes: a ala social também auxiliava no papel agregador pretendido pelas agremiações (QUITZAU, 2013; SILVA; MAZO, 2015). As associações esportivas, com um modelo notadamente inspirado nos clubes ingleses organizados desde o final do século XIX, se inseriram em uma lógica moderna de sociabilidade, baseada na contenção da violência, domínio das pulsões e em novas representações dos papéis sociais dos indivíduos (RIOUX, 1986; ARNAUD, 1986; ELIAS, 1992).

No Brasil, esse modelo funcionou como um meio bastante profícuo de alcançar certa distinção social, não só pelas representações esportivas, mas também pelas festas, eventos e bailes. Pereira (2017), em estudo sobre os clubes sociais cariocas da primeira metade do século XIX, aponta que os eventos dançantes tinham centralidade na programação social. Gomes, Quitzau e Moraes e Silva (2020) investigaram festividades dançantes nos clubes curitibanos no início do século $X X$, e concluíram que estes eram eventos que congregavam novas formas de se comportar 
e estabelecer relações interpessoais, bastante associadas aos discursos da cultura física promovidos na época.

O periódico A Onda, bastante interessado nos eventos sociais da cidade de Campinas, divulgava com frequência os festejos realizados pelo C.C.R.N. Em geral, as comemorações que tomavam parte no final de semana contavam com a somatória de competições esportivas e baile ao ar livre, realizado no fim da tarde, e abrilhantados com a "fina flor da sociedade" (CLUB..., 1921, p.13).

Os eventos se adaptavam à época do ano e à importância dos convidados. Em janeiro de 1922, foi noticiada uma festa veneziana, que ocorreria entre os associados nos próximos dias, e que contaria com batalhas de confetes e serpentinas, seguidas de um grande baile, que se prolongaria até às 23 horas (ROWING, 1922).

Um dos mais importantes eventos sociais promovido pela associação esportiva era o "banho à fantasia". Nesse evento "tomaram parte todos os nadadores" e contava-se, inclusive, com visitantes de outras cidades, como São Paulo, Piracicaba e Ribeirão Preto. Era um festejo carnavalesco, em que os associados se fantasiavam e brincavam nas águas do rio. Às melhores fantasias eram distribuídas premiações: "o sr. Moacyr Segurado obteve um premio por ser sua fantasia a mais espirituosa" (AQUATICA, 1925, p.4).

Gomes, Quitzau e Moraes e Silva (2020) analisaram que os bailes e festividades no Clube Curitibano fizeram emergir novas formas de se comportar e estabelecer relações interpessoais naquela sociedade, que atingiram o patamar da utilidade quando foram atreladas aos discursos da cultura física. No caso do C.C.R.N., é possível afirmar que esses festejos também se atrelaram aos intuitos da associação de difundir uma nova cultura física, pautada em moral, normas e práticas, que acabaram por transformar esse espaço da cidade.

Desse modo, poderíamos afirmar que a singela e pacata vida às margens do rio Atibaia em sua extensão do Arraial de Sousas foi, pouco a pouco, sendo atravessada pelos valores urbanos que carregavam consigo novas sensibilidades e inéditas relações com a natureza. As novas práticas corporais e os novos comportamentos levados a cabo pelo C.C.R.N. certamente transformaram aquele espaço, antes "uma minúscula gleba povoada" (BIANCHI, 1964, p.1).

\section{CONSIDERAÇÕES FINAIS}

A instalação do C.C.R.N. às margens do rio Atibaia mudou a relação existente, até aquele momento, entre parte da população campineira e o rio que banhava a extensão da cidade. Até 1918, ano em que alguns jovens decidiram criar um clube para a prática de esportes náuticos em Campinas, não há registros de práticas esportivas no rio. As fotografias encontradas apontam ora para práticas voltadas ao divertimento da população local, como a pescaria, ora para usos próprios ao mundo do trabalho ou ao transporte. A instalação do clube permitiu a difusão de novas práticas e novos comportamentos em suas margens: estabelecia-se assim uma cultura física que transformaria a relação de parte da população com as águas do Atibaia. 
A criação do C.C.R.N. exigiu, a priori, modificações na natureza local. O intuito era permitir um melhor aproveitamento das águas que ali corriam e do terreno que margeava a região, tornando-os adequados às práticas esportivas. Os serviços contaram com a retirada de pedras, a retificação do solo, a instalação de novas linhas de bonde. O local, distante do centro da cidade, ganhava paulatinamente novos visitantes e frequentadores, ainda que o acesso fosse precário. Assim, a natureza e seus elementos foram alterados a partir da mão humana, para tornar possíveis os novos usos desejados para aquele espaço.

Para além das alterações no rio e suas margens, havia também mudanças nos comportamentos que sugeriam formas até então inéditas de usos da natureza e seus elementos. Uma exortação da vida ao ar livre era proferida em discursos médicos, pedagógicos, esportivos e largamente divulgada na imprensa.

Eram inúmeras as atividades evocadas nesse novo ideário de vida ao ar livre conforme pudemos constatar em nossas fontes e, entre elas, estavam as festas, bailes, piqueniques e, sem dúvida, os esportes, que se fizeram notar tanto como prática quanto como espetáculo.

Assim, o clube foi, pouco a pouco, consolidando divertimentos que expressavam de maneira intensa ideias e ideais urbanos modernos, como era bem o caso do esporte no período. Em consonância às definições de Kirk (1999), pode-se afirmar que, em sentidos múltiplos, havia o desejo da promoção de uma cultura física a seus associados, que exortava a vida ao ar livre e o contato com a natureza, no período ora analisado.

\section{REFERÊNCIAS}

AMENDOLA, João. Outros tempos... Diário do Povo, Campinas, 26 maio 1961.

AQUATICA regional. A Gazeta, São Paulo, p. 4, 18 fev. 1925.

ARNAUD, Pierre. Pratiques et pratiquants: les transformations de la sociabilité sportive. L'exemple de Lyon et du département du Rhône entre 1850 et 1914. In: ARNAUD, Pierre; CAMY, Jean. La Naissance du mouvement sportif associatif en France: sociabilités et formes de pratiques sportives. Lyon: Presses Universitaires de Lyon, 1986. p. 173-198.

BADARÓ, Ricardo. Campinas: o despontar da modernidade. Campinas: Área de Publicações CMU/UNICAMP, 1996.

BIANCHI, João. Algo novo no Grupo dos Remidos. O regateiro - órgão oficial de divulgação do Clube Campineiro de Regatas e Natação. Campinas, ago. 1964.

BOURDIEU, Pierre. Como é possível ser esportivo? In: BOURDIEU, Pierre. Questões de sociologia. Lisboa: Fim de século, 2003. p.171-204.

CARPINTÉRO, Maria Varanda. Arte, técnica e política na trajetória de Francisco Prestes Maia. URBANA: Revista Eletrônica do Centro Interdisciplinar de Estudos sobre a Cidade, v. 5, n. 2, p. 20-46, 2013. Disponível em: https://periodicos.sbu.unicamp.br/ojs/index.php/ urbana/article/view/8635074. Acesso em: 19 mar. 2021. 
CLUB Campineiro de Regatas e Natação. A Onda, ano 1, n. 6, p.13, 31 jul. 1921.

O CLUB de natação e regatas de Piracicaba é o primeiro fundado no interior do estado. A Gazeta, São Paulo, p. 2, 18 mar. 1918a.

O CLUB de regatas campineiro. A Gazeta, São Paulo, p. 2, 21 mai. $1918 b$.

CLUBE Campineiro de Regatas e Natação. A Gazeta, p. 3, 03 fev. 1923.

A CONVITE..., A Gazeta, São Paulo, 19 jun. 1922.

CORBIN, Alain. L'homme dans le paysage. Paris: Textuel, 2001.

CORREAA, Livia Cristina. Campinas n'A Onda: a revista inscreve a cidade na modernidade (1921-1924). 2014. 132 f. Dissertação (mestrado em história) - Instituto de Filosofia e Ciências Humanas, Universidade Estadual de Campinas, 2014.

DALBEN, André. Educação do corpo e vida ao ar livre: natureza e educação física em São Paulo (1930-1945). 2009. 158f. Dissertação (mestrado em educação física) Faculdade de Educação Física, Universidade Estadual de Campinas, 2009.

DALBEN, André. Mais do que energia, uma aventura do corpo: as colônias de férias escolares na América do Sul (1882-1950). 2014. 389p. Tese (doutorado em educação) Faculdade de Educação, Universidade Estadual de Campinas, 2014.

DALBEN, André. Notas sobre a cidade de São Paulo e a natureza de seus parques urbanos. Urbana - Revista Eletrônica do Centro Interdisciplinar de Estudos da Cidade, v. 8, p. 3-27, 2016.

DALBEN, André; SILVA, Henrique Mendonça da. Sol e ar fresco no combate à tuberculose: experiências de educação ao ar livre no Rio de Janeiro (1910-1920). Cadernos CEDES, v. 40, p. 218-232, 2020.

DIAS, Douglas da Cunha. Quem te margeia conta de ti: educação do corpo na Belém do Grão-Pará (de 1855 à década de 1920). 2014. 484f. Tese (Doutorado em educação) Faculdade de Educação, Universidade Estadual de Campinas, SP. 2014.

DIAS, Douglas Cunha.; SOARES, Carmen Lúcia. Entre velas, barcos e braçadas: Belém no espelho das águas (do final do século XIX à década de 1920). Projeto História, v. 49, p. 19-49, 2014. Disponível em: https://revistas.pucsp.br/revph/article/view/19712. Acesso em 19 mar. 2021.

ELIAS, Norbert. A gênese do desporto: um problema sociológico. In: ELIAS, Norbert; DUNNING, Eric. A busca da excitação. Lisboa: Difel, 1992. p.39-99.

EM FESTAS o CCRN com o 43 aniversário de sua fundação. Diário do Povo, Campinas, 26 maio 1961.

GAMBETA, Wilson. A bola rolou: o Velódromo Paulista e os espetáculos de futebol, 18951916. 2014. 408p. Tese (doutorado em história) - Faculdade de Filosofia, Letras e Ciências Humanas, Universidade de São Paulo, São Paulo, 2014.

GOMES, Leonardo Couto; QUITZAU, Evelise Amgarten; MORAES E SILVA, Marcelo. As festividades dançantes no Clube Curitibano: os bailes como elemento da cultura física (1881-1914). History of Education in Latin America - HistELA, v. 3, e19729, 2020. Disponível em: https://periodicos.ufrn.br/histela/article/view/19729. Acesso em 19 mar. 2021.

KIRK, David. Physical Culture, Physical Education and Relational Analysis. Sport, Education and Society, v. 4, n. 1, p. 63-73, 1999. 
KOSSOY, Boris. Fotografia \& história. 4. ed. rev. São Paulo: Ateliê, 2012.

LAPA, José Roberto do Amaral. A cidade: Os cantos e os antros. Campinas 1860-1900. São Paulo: EDUSP, 2008.

LE GOFF, Jacques; NORA, Pierre (org.). História: novos problemas. 3.ed. Rio de Janeiro: Francisco Alves, 1988.

LENOBLE, Robert. História da ideia de natureza. Rio de Janeiro: Edições 70, 1990.

LUCENA, Ricardo Figueiredo. O esporte na cidade: aspectos do esforço civilizador brasileiro. Campinas, SP: Autores Associados: CBCE, 2001.

MEDEIROS, Daniele Cristina Carqueijeiro. Dos desafios aquáticos ao estabelecimento de recordes: aproximação e distanciamento entre práticas esportivas e os rios da cidade de São Paulo (1899-1949). Revista Brasileira de Ciências do Esporte, v. 42, p. e2040, 2020. Disponível em: https://www.scielo.br/scielo.php?pid=S0101-

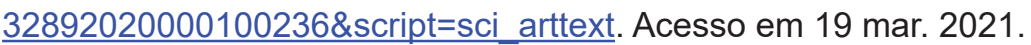

MEDEIROS, Daniele Cristina Carqueijeiro. Entre esportes, divertimentos e competições: a cultura física nos rios Tietê e Pinheiros (São Paulo, 1899-1949). 2021. 264p. Tese (Doutorado em educação) - Faculdade de Educação, Universidade Estadual de Campinas, SP, 2021.

MELO, Victor Andrade. O mar e o remo no Rio de Janeiro do século XIX. Estudos Históricos, v. 13, n. 23, p. 41-60, 1999. Disponível em: http://bibliotecadigital.fgv.br/ojs/ index.php/reh/article/view/2088. Acesso em: 19 mar. 2021.

MELO, Victor Andrade. Cidade sportiva: primórdios do esporte no Rio de Janeiro. Rio de Janeiro: Relume Dumará: FAPERJ, 2001.

MELO, Victor Andrade; SANTOS, João Manuel Casquinha Malaia. "Casa sportman sempre imitada, nunca igualada": estratégias de um empreendimento e dinâmicas de consumo (Rio de Janeiro, 1909-1922). História econômica e história de empresas, v. 23, n. 2, p.495-525, 2020. Disponível em: https://www.hehe.org.br/index.php/rabphe/article/ view/752. Acesso em 30 jun. 2021.

MONTENEGRO, Nara Romero. A cultura física e suas manifestações no litoral de Fortaleza (1925-1946): novos modos de se educar e de se divertir. 2020. 160f. Dissertação (Mestrado em educação) - Faculdade de Educação, Universidade Estadual de Campinas, 2020.

MORAES E SILVA, Marcelo. Novos modos de olhar outras maneiras de se comportar: a emergência do dispositivo esportivo da cidade de Curitiba (1899-1918). 2011. 227f. Tese (Doutorado em educação) - Faculdade de Educação, Universidade Estadual de Campinas, 2011.

MORAES E SILVA, Marcelo; QUITZAU, Evelise Amgarten. A cultura física na cidade de Curitiba: a emergência de uma pedagogia corporal (1899-1909). Revista de Ciencias Sociales, v. 27, n. 41, p. 275-296, 2018. Disponível em: http://www.revistacienciasociales.cl/ ojs/index.php/publicacion/article/view/130. Acesso em: 19 mar. 2021.

MORAES E SILVA, Marcelo; QUITZAU, Evelise Amgarten; SOARES, Carmen Lúcia. Práticas educativas e de divertimento junto à natureza: a cultura física em Curitiba (18861914). Educação e Pesquisa, Universidade de São Paulo - São Paulo, v. 44, p. 178-293, 2018. Disponível em: https://www.scielo.br/scielo.php?script=sci_abstract\&pid=S151797022018000100495\&lng=pt\&nrm=is. Acesso em: 19 mar. 2021. 
MUSA, Catharina Ulian. Em meio à natureza... nasce o Clube Campineiro de Regatas e Natação (1918-1935). 2021. 48f. Trabalho de Conclusão de Curso (Graduação). Faculdade de Educação Física, Universidade Estadual de Campinas (Unicamp), 2021.

NAUTICA. A Gazeta, p. 4, 08 maio 1924.

NICOLINI, Henrique. Tietê: o rio do esporte. São Paulo: Phorte, 2001.

A ONDA, Campinas, ano 4, n. 70, 29 jun. 1924

PALOMBO, Darci Maria Paschoal. Clube Campineiro de Regatas e Natação: oitenta e dois anos de História, Oitenta e dois anos de Glórias. Campinas: Clube da Bandeirantes Indústria Gráfica, 2000.

PEREIRA, Leonardo Affonso de Miranda. A dança da política: trabalhadores, associativismo recreativo e eleições no Rio de Janeiro da Primeira República. Revista Brasileira de História, v. 37, n. 74, p. 63-88, 2017. Disponível em: https://www.scielo.br/scielo. php?script=sci_abstract\&pid=S0102-01882017000100063\&lng=pt\&nrm=iso\&tlng=pt. Acesso em: 19 mar. 2021.

O QUE O TEMPO não apaga. Correio Popular, Campinas, 18 mai. 1973.

QUITZAU, Evelise Amgarten. Different Clubs, Similar Purposes? Gymnastics and Sports in the German Colony of São Paulo/Brazil at the Turn of the Nineteenth Century. The International Journal of the History of Sport, v. 30, p. 963-975, 2013.

QUITZAU, Evelise Amgarten. Entre a ginástica e o esporte: educação do corpo e manutenção da identidade nas sociedades ginásticas teuto-brasileiras. Educação em Revista, v. 35, p. e217174, 2019. Disponível em: https://www.scielo.br/scielo.php?script=sci arttext\&pid=S010246982019000100807\&lng=pt\&nrm=iso\&tlng=pt. Acesso em: 19 mar. 2021.

REGATAS atinge hoje meio século. Diário do Povo, Campinas, 18 mai. 1968.

REGATAS patrimônio esportivo da cidade. Correio Popular, Campinas, p. 2, 4 set. 1938.

REMO e natação. A Onda, Campinas, ano 1, n. 4, p.8, 26 jun. 1921.

RIOUX, Jean. Sport et association: remarques de precaution. In: ARNAUD, Pierre; CAMY, Jean. La Naissance du mouvement sportif associatif en France: sociabilités et formes de pratiques sportives. Lyon: Presses Universitaires de Lyon, 1986.

ROUSSEAU, Jean-Jacques. Discurso sobre a origem e fundamentos da desigualdade entre os homens. São Paulo: Martins Fontes, 1976-

ROUSSEAU, Jean-Jacques. Emílio ou Da Educação. Rio de Janeiro : Bertrand Brasil, 1992-

ROWING. A Onda, Campinas, ano 1, n. 17, p.12, 15 jan. 1922.

ROXO, Rafael. A formação urbana de Campinas (SP): de pouso à margem do caminho do ouro a lugar mundial. GEOSUL: Revista do Departamento de Geociências, v. 35, n.74, p. 38-63, jan/abr, 2020. Disponível em: https://periodicos.ufsc.br/index.php/geosul/article/ view/1982-5153.2020v35n74p38. Acesso em: 19 mar. 2021.

SILVA, Carolina Fernandes. O remo e a história de Porto Alegre, Rio Grande do Sul: mosaico de identidades culturais no longo século XIX. 2011. 151f. Dissertação (Mestrado em Ciência do Movimento Humano) - Programa de Pós Graduação em Ciências do Movimento Humano, Universidade Federal do Rio Grande do Sul, Porto Alegre, RS. 2011. 
SILVA, Carolina Fernandes; MAZO, Janice. Uma história das instrumentalidades do esporte no campo do associativismo esportivo em Porto Alegre/RS. Movimento (ESEFID/UFRGS), v. 21, n. 2, p. 377-389, fev. 2015. Disponível em: https://seer.ufrgs.br/Movimento/article/ view/48215. Acesso em: 19 mar. 2021.

SILVA, Carolina Fernandes et al. Associações de remadores teuto-brasileiros em Porto Alegre (1917): recomposições identitárias em um conflito bélico. Journal of Physical Education, v. 27, p. 2720, 2016. Disponível em: https://www.scielo.br/scielo. php?pid=S2448-24552016000100118\&script=sci abstract\&tlng=pt. Acesso em: 19 mar. 2021.

SILVA, Carolina Fernandes; MAZO, Janice; TAVARES, Otavio. O estabelecimento dos esportes náuticos no Rio Grande do Sul na primeira década do século XX: entre o ruder e o remo. Revista brasileira de ciências do esporte, v. 40, n.1, p. 24-31, 2018. Disponível em: https://www.scielo.br/scielo.php?pid=S0101-32892018000100024\&script=sci abstract\&tlng=pt. Acesso em: 19 mar. 2021.

SIQUEIRA, Sandra Aparecida. Campinas, seus corpos, suas águas (práticas corporais aquáticas no início do século XX). 2009. 106f. Dissertação (Mestrado em educação física) Faculdade de Educação Física, Universidade Estadual de Campinas, Campinas, 2009.

SOARES, Carmen Lúcia. As roupas nas práticas corporais e esportivas: a educação do corpo entre o conforto, a elegância e a eficiência (1920-1940). Campinas-SP: Autores Associados, 2011.

SOARES, Carmen Lúcia. Três notas sobre natureza, educação do corpo e ordem urbana (1900-1940). In: SOARES, C.L. (org.) Uma educação pela natureza: a vida ao ar livre, o corpo e a ordem urbana. Campinas, SP: Autores Associados, 2016.

SONTAG, Susan. Sobre fotografia. São Paulo: Companhia das Letras, 2004.

THOMAS, Keith. O homem e o mundo natural: mudanças de atitude em relação às plantas e aos animais. São Paulo: Companhia das Letras, 1988.

TíRICO, José Domingos. Sousas, subúrbio de Campinas. Boletim Paulista de Geografia, n.35, p. 32-54, jul. 1960. Disponível em: https://publicacoes.agb.org.br/index.php/boletimpaulista/article/view/1228/1075. Acesso em: 19 mar. 2021.

TOLEDO, Luís Henrique. A cidade e o jornal: a Gazeta Esportiva e os sentidos da modernidade na São Paulo da primeira metade do século XX. In: HOLLANDA, Bernardo; MELO, Victor Andrade (org.). $O$ esporte na imprensa e a imprensa esportiva no Brasil. Rio de Janeiro: 7 Letras, 2012. p. 52-77.

VIGARELLO, Georges. Du jeu ancien au show sportif: la naissance d'un mythe. Paris : Éditions Seuil, 2002.

VIGARELLO, Georges. "Treinar". In : VIGARELLO, Georges; CORBIN, Alain; COURTINE Jean Jacques. História do Corpo: as mutações do olhar - o século XX. São Paulo: Vozes, 2008. v. 2, p. 197-252.

VILLARET, Sylvain. Histoire du naturisme en France depuis le siècle des Lumières. Paris: Vuibert, 2005.

VILLARET, Sylvain. Naturismo e educação corporal (fim do século XIX e início do século $X X)$ : uma natureza em movimento. In: SOARES, Carmen Lucia. Uma educação pela natureza: a vida ao ar livre, o corpo e a ordem urbana. Campinas: Autores Associados, 2016. p. 69-90. 
Abstract: The Campineiro Rowing and Swimming Club (CCRN) was created in 1918, by the banks of the Atibaia River in the region of Sousas, a rural area near the city of Campinas. In 1935, its facilities were expanded and an urban core was created in the city center. Considering this brief period of time (1918-1935), this work examines how the creation of this club affected the relationship of the local population with the natural environment, leading to the development of new practices and behaviors involving physical activity. Information sources included newspapers, magazines, and photographs, as well as newspaper clippings. The findings showed that the practices introduced by the club transformed the landscape and the behavior of the population participating in them, who were encouraged to engage in outdoor activities, modifying the way that the river was used as a natural resource.

Keywords: Water sports. History. Nature. Culture

Resumen: El Club Campinero de Regatas y Natación (CCRN) fue creado en 1918, a las márgenes del río Atibaia, en la región de Sousas, zona rural de Campinas y, en 1935, amplió sus dependencias con la creación de una sede urbana en el centro de la ciudad. En el ámbito de ese breve recorte de tiempo (1918 a 1935), el artículo examina cómo la creación del club transformó la relación de parte de la población local con la naturaleza y sus elementos, donde nuevas prácticas y conductas relacionadas a la cultura física pasaron a tener lugar. Las fuentes constituidas incluyen periódicos, revistas, fotografías, así como recortes sueltos de periódicos. Se concluye que las nuevas prácticas realizadas por el club transformaron el paisaje y los comportamientos, que pasaron a exhortar a una vida al aire libre, así como transformaron también la manera en que el río era utilizado por parte de los habitantes de la ciudad.

Palabras clave: Deportes acuáticos. Historia. Naturaleza. Cultura. 


\section{LICENÇA DE USO}

Este é um artigo publicado em acesso aberto (Open Access) sob a licença Creative Commons Atribuição 4.0 Internacional (CC BY 4.0), que permite uso, distribuição e reprodução em qualquer meio, desde que o trabalho original seja corretamente citado. Mais informações em: https://creativecommons.org/licenses/by/4.0

\section{CONFLITO DE INTERESSES}

Os autores declararam que não existe nenhum conflito de interesses neste trabalho.

\section{CONTRIBUIÇÕES AUTORAIS}

Catharina Ulian Musa: Conceituação, produção de fontes, análise de dados, investigação, produção de metodologia, escrita.

Daniele Cristina Carqueijeiro de Medeiros: Conceituação, produção de fontes, análise de dados, investigação, produção de metodologia, escrita, editoração.

Carmen Lúcia Soares: Conceituação, produção de fontes, análise de dados, investigação, produção de metodologia, escrita, supervisão.

\section{FINANCIAMENTO}

O presente trabalho foi realizado com apoio do Conselho Nacional de Desenvolvimento Científico e Tecnológico (CNPq) modalidades PQ-Bolsa de Produtividade em Pesquisa-nível2 e PIBIC-Bolsa de Iniciação Científica.

\section{COMO REFERENCIAR}

MUSA, Catharina Ulian; MEDEIROS, Daniele Cristina Carqueijeiro de; SOARES, Carmen Lúcia. "Moços intrépidos ao leo da aventura": o Clube Campineiro de Regatas e Natação e a vida ao ar livre (1918-1935). Movimento (Porto Alegre), v.27, p.e27045, jan./dez. 2021. Disponível em: https://seer.ufrgs.br/Movimento/ article/view/113709. Acesso em: [dia] [mês abreviado]. [ano]. DOI: https://doi. org/10.22456/1982-8918.113709

\section{RESPONSABILIDADE EDITORIAL}

Alex Branco Fraga*, Elisandro Schultz Wittizorecki*, Ivone Job*, Mauro Myskiw*, Raquel da Silveira*

*Universidade Federal do Rio Grande do Sul, Escola de Educação Física, Fisioterapia e Dança, Porto Alegre, RS, Brasil. 